\title{
OBSTETRIC OUTCOME IN SHORT STATURED WOMEN- A TERTIARY CARE REFERRAL CENTRE EXPERIENCE FROM SOUTH INDIA
}

\author{
Lisha Govind K. V1, Rajesh T. V2
}

${ }_{1}^{1}$ Assistant Professor, Department of Obstetrics and Gynaecology, KMCT Medical College, Manassery, Kozhikode, Kerala. ${ }^{2}$ Associate Professor, Department of Paediatrics, Government Medical College, Kozhikode, Kerala.

\begin{abstract}
BACKGROUND
ABSTRACT

Maternal height is one of the parameters which significantly affects the obstetric performance. Short statured women may have small pelvis and are reported to have higher rates of perinatal mortality, low birth weight and operative delivery.

Objective- To find out the relationship between maternal height and obstetric outcome with emphasis on the mode of delivery and neonatal outcome.
\end{abstract}

\section{MATERIALS AND METHODS}

This Descriptive study was carried out in the Department of Obstetrics and Gynaecology, Institute of Maternal and Child Health (IMCH), Govt. Medical College, Kozhikode, over a period of one year from November 2007 to October 2008. Since the study duration was short, we had to limit the sample size for convenience. Primigravida having singleton pregnancies, cephalic presentation and sure date of LMP with no medical and obstetric complications were selected from antenatal clinic of IMCH. Those with height $\leq 145 \mathrm{~cm}$ formed and those with height $>145 \mathrm{~cm}$ formed were considered. A semi-structured proforma which contain demographic, antenatal and anthropometric details as well as obstetric and neonatal outcomes were recorded. Pregnancy and foetal outcome were compared using student's ' $t$ ' test and chi-square test.

\section{RESULTS}

Out of 467 primigravida, 227 women with height $<145 \mathrm{~cm}$ formed the study group and the rest 240 formed the control group. The incidence of LSCS in short women was $32.1 \%$ compared to $10 \%$ in tall women ( $<<0.001$ ), which is highly significant. In short statured women, 53\% had LSCS due to CPD, whereas in taller women $25 \%$ had LSCS for CPD (Z= 4.525, P < 0.0001). CPD was the indication for LSCS in 71.4\% of mothers with height $<135 \mathrm{~cm}$ and the percentage of CPD decreased with increase in the maternal height. Significant number of babies born to short statured mothers were asphyxiated (11\% vs $3.33 \%$ ) and required NICU admission (17.6\% vs $4.58 \%$ ) in comparison to babies born to mothers of control group.

\section{CONCLUSION}

Women with short stature are high-risk population for poor pregnancy outcome. Short statured women are more likely to undergo LSCS for CPD and their babies are more asphyxiated at birth with higher rate of NICU admissions. The need for anthropometric assessment, partographic monitoring, prompt identification of CPD and early possible caesarean section as well as prompt neonatal care are crucial in the prevention of adverse maternal and perinatal morbidity in short statured women.

\section{KEYWORDS}

Maternal Height, Short Stature, Cephalopelvic Disproportion, Obstructed Labour, Perinatal Morbidity.

HOW TO CITE THIS ARTICLE: Govind LKV, Rajesh TV. Obstetric outcome in short statured women- a tertiary care referral centre experience from South India. J. Evolution Med. Dent. Sci. 2018;7(12):1440-1442, DOI: 10.14260/jemds/2018/327

\section{BACKGROUND}

Outcome of labour is influenced by many factors. Age of mother, parity, health and physique of the mother, standard obstetric care and coexisting diseases alter the outcome of labour.[1] Antenatal care is an important area where obstetrician can contribute significantly for preventing pregnancy complications. Recognition of cephalopelvic disproportion (CPD) and prediction of low birth weight (LBW) foetus is one of the important factors in antenatal care. Maternal height is one of the parameters, which significantly affects the obstetric performance.[2]

'Financial or Other Competing Interest': None.

Submission 06-02-2018, Peer Review 02-03-2018,

Acceptance 09-03-2018, Published 19-03-2018.

Corresponding Author:

Dr. Rajesh T. $V$,

Nikunjam, 30/433 B1,

Chevayur- P. O., Kozhikode-673017,

Kerala.

E-mail:drrajeshtv@gmail.com

DOI: $10.14260 /$ jemds $/ 2018 / 327$

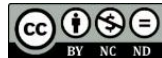

Stature is found to be significantly related to several pelvic indices. Short statured women may have small pelvis, a matter of concern during pregnancy and childbirth. Baird (1957) was among the first to correlate the health and physique of the women with their reproductive efficiency. Short women are reported to have higher rates of perinatal mortality, low birth weight and operative delivery. Maternal height influences the outcome in all social classes.[3]

A significantly higher evidence of generally contracted pelvis in the short mother group is conspicuous. The labour subsequently gets prolonged and obstructed, which in turn leads to ruptured uterus, a complication which can totally be prevented. Maternal and foetal death, birth asphyxia and VVF caused by unrecognised disproportion between foetus and pelvis can also be prevented by timely and appropriate intervention before or during labour.[4] So detection of CPD is one of the main goals of antenatal clinics. Preterm and LBW babies contribute a major portion of mortality and morbidity. [3]

Based on WHO meta-analysis, height of $145 \mathrm{~cm}$ has been identified as the $10^{\text {th }}$ percentile. ${ }^{[4]}$ Many authors mention 145 
$\mathrm{cm}$ as the cut-off for the identification of short statured women. ${ }^{[3,5,6,7]}$ Efficient and effective antenatal screening is an essential part of any strategy to identify the short statured women and to reduce the associated maternal and foetal complications.

Maternal short stature having been identified as a risk factor for operative delivery and poor perinatal outcome, it is relevant to identify the problems associated with the same, in patients of a tertiary care institution which cater people of middle and lower socioeconomic class from five northern districts of Kerala.

\section{Objective}

To find out the relationship between maternal height and obstetric outcome with emphasis on the mode of delivery and neonatal outcome.

\section{MATERIALS AND METHODS}

This was a Descriptive study carried out in the Department of Obstetrics and Gynaecology, Institute of Maternal and Child Health (IMCH), Govt. Medical College, Kozhikode. The study was conducted over a period of one year from November 2007 to October 2008.

\section{Inclusion Criteria}

Primigravida having singleton pregnancy, cephalic presentation and sure date of LMP with no medical and obstetric complications were selected from antenatal clinic of IMCH. Those with height $\leq 145 \mathrm{~cm}$ formed and those with height $>145 \mathrm{~cm}$ formed were considered.

\section{Exclusion Criteria}

Pregnant women with any medical and obstetric complications were excluded. The study was approved by the Institutional Ethical Committee and written informed consent was obtained from all women included in the study group. Since the study duration was short, we had to limit the sample size for convenience. Study of data was collected from admitted pregnant women who satisfied selection criteria by personal interview and review of records. A proforma containing details like age, occupation, education, socioeconomic status and a detailed obstetric history including menstrual history, contraception, history of present pregnancy, antenatal care and details of ultrasonography was recorded. The socioeconomic status was assessed according to Kuppuswamy's Socioeconomic status scale. Maternal height was measured with the patient standing erect without shoes on a flat base against the wall with a standard scale in centimetre. Examination of the woman including detailed abdominal examination to confirm fundal height, foetal lie and presentation were carried out. Foetal heart rate and rhythm were noted by auscultation. Assessment of pelvis for adequacy was done. Once in labour, duration of labour, mode of delivery, its effect on the foetus etc. were noted. Baby details like weight, Apgar score, admission to NICU, morbidity and mortality were also recorded.

\section{Statistical Analysis}

Pregnancy and foetal outcome in study groups are compared using SPSS software version 6.1 to calculate student's ' $t$ ' test and chi-square test. The value considered significant when ' $p$ ' value is less than or equal to 0.05 .

\section{RESULTS}

A total of 467 primigravida were taken up for the study. Out of this, 227 women with height $<145 \mathrm{~cm}$ formed the study group and the rest 240 formed the control group. Various parameters of both groups were studied and analysed. Both groups were of age between 19 and 40 yrs. Majority of the confinements occurred between 20 and 24 yrs. For the analysis, details of each subject were grouped together according to different height range. Significant number of short statured women were of height between 140 and 144 $\mathrm{cm}$. The shortest mother of the study group had a height of $131 \mathrm{~cm}$. Majority of the control group were of height ranging between 150 and $160 \mathrm{cms}$, and the tallest was $173 \mathrm{~cm}$. Majority of the mothers of study group as well as control group belonged to poor socioeconomic status. Out of 227 short women, $75.77 \%$ were in social class $\mathrm{V}$.

Mode of delivery in different height groups is shown in Table 1. The incidence of LSCS in short women was $32.1 \%$ compared to $10 \%$ in tall women, ( $<<0.001$ ), which is highly significant. In short statured women $53 \%$ had LSCS due to CPD, whereas in taller women $25 \%$ had LSCS for CPD and this difference is statistically significant $(\mathrm{Z}=4.525, \mathrm{P}<0.0001)$. CPD was the indication for LSCS in $71.4 \%$ of mothers with height $<135 \mathrm{~cm}$ and the percentage of CPD decreased with increase in the maternal height. Rate of instrumental delivery in study group $(7.9 \%)$ was not significantly different from control group.

The incidence of LBW babies in study group was $31.2 \%$ and that of control group was $23.3 \%$ and the difference was not significant ( $p-0.074)$. Number of babies, weighing $>3 \mathrm{~kg}$, was 2.6 times more in tall women compared to that in short women, which was statistically significant. In short mothers, rate of LSCS increased significantly from $13.89 \%$ when birth weight was less than $2.5 \mathrm{~kg}$ to $39.13 \%$ with babies weighing more than $2.5 \mathrm{~kg}$.

Significant number of babies born to short statured mothers (11\%) had an Apgar score of less than 7 at 5 minutes in comparison to that of mothers with height more than 145 $\mathrm{cm}$ (3.33\%). Among the babies of short mothers, $17.6 \%$ required NICU admission compared to $4.58 \%$ of babies born to mothers of control group, which was statistically significant.

\begin{tabular}{|c|c|c|c|c|c|}
\hline \multirow{2}{*}{$\begin{array}{c}\text { Mode of } \\
\text { Delivery }\end{array}$} & $\begin{array}{c}\text { Study Group } \\
\mathbf{n = 2 2 7}\end{array}$ & \multicolumn{2}{c|}{$\begin{array}{c}\text { Control Group } \\
\mathbf{n = 2 4 0}\end{array}$} & \multirow{2}{*}{ v value } \\
\cline { 2 - 5 } & Number & $\mathbf{\%}$ & Number & $\mathbf{\%}$ & \\
\hline Vaginal & 140 & 61.6 & 197 & 82.08 & 0.054 \\
\hline Instrumental & 14 & 7.9 & 19 & 7.9 & 0.079 \\
\hline LSCS & 73 & 32.1 & 24 & 10 & $<0.001$ \\
\hline Table 1. Mode of Delivery in Case and Control Groups \\
\hline
\end{tabular}

\section{DISCUSSION}

Maternal height is one of the important parameters, which influences the obstetric outcome. The main aim of this study was to find out the association of maternal height with mode of delivery and neonatal outcome.

The present study suggests that women of short stature belong to a higher risk group regarding obstetric outcome. The rate of LSCS in short statured women was significantly higher than that of taller women $(32.1 \%$ vs $10 \%)$. The independent risk for LSCS in a short woman was 2.5 times higher according to Baird. Mahmood et al also found a significantly higher rate of LSCS in women of short stature.[8] 
Kappel et al[9] observed that the prevalence rate for emergency LSCS was 3-fold higher in short mothers and the prevalence rate for elective LSCS also found a similar risk by LY Hin et al.[10]

The vaginal delivery rate in short mothers was lower than that in taller women $(61.67 \%$ vs $82.08 \%)$, even though the difference was not significant. Similar observations were made by Desai et al[3] and Bhatt et al.

CPD was the indication for LSCS in 53\% of short women, whereas only $25 \%$ of the taller women had LSCS for CPD. The overall incidence of CPD among short women was $16.7 \%$ compared to $2.5 \%$ in taller women. Parson et al[11] and Pradhan N et al[12] also observed a higher rate of LSCS due to CPD among short statured women and their LSCS rates were $35.45 \%$ and $36.6 \%$ respectively. In the present study about $71 \%$ mothers with height less than $135 \mathrm{~cm}$, CPD was the indication for LSCS and the percentage of CPD decreased as the maternal height increased showing that maternal height has a definite influence on the mode of delivery.

Babies weighing more than $3 \mathrm{~kg}$ were 2.6 times more in tall mothers compared with short mothers ( $\mathrm{p}<0.001)$, but the difference in the incidence of LBW babies in both groups was not significant (study group: $31.2 \%$ and control group: $23.3 \%$ ). Similar observation was made by T Kamaldoss et al in 1992,[13] where the incidence of LBW babies among mothers with height $<145$ and $\geq 145$ were $29.7 \%$ and $24.2 \%$ respectively.

In short mothers, rate of LSCS increased significantly with increase in birth weight of the baby (from $13.89 \%$ when birth weight was less than $2.5 \mathrm{~kg}$ to $39.13 \%$ with babies weighing more than $2.5 \mathrm{~kg}$ ). The possibility of vaginal delivery decreases as the baby weight increases in mothers with short stature. In the present study, $86.1 \%$ of the short mothers with LBW babies were delivered through vaginal route explaining the fact that vaginal delivery is possible in short women when they have small babies.

Higher incidence of birth asphyxia was found in babies of short women compared to babies of women of normal stature (babies with Apgar score of less than 7 at 5 minutes: 11\% vs $3.33 \%$ ). Also, the risk for NICU admission is twice in them. Results of present study is comparable to previous studies by AP Camilleri[14] and Mohamed et al.[15]

\section{Limitations}

Since the study duration was short, we had to limit the sample size for convenience.

\section{CONCLUSION}

Women with short stature (height $\leq 145 \mathrm{~cm}$ ) are high risk population for poor pregnancy outcome. Mode of delivery is influenced by maternal height, the short statured women being more likely to undergo LSCS for CPD. Babies born to short mothers are more asphyxiated at birth and their rate of NICU admission is higher. Even though significant number of larger babies is born to taller mothers, there is no increase in the risk for having LBW babies in the short mothers. In mothers with short stature, rate of LSCS increases and vaginal delivery decreases as the birth weight of the baby increases. Socioeconomic status has a definite influence on maternal height and therefore in the obstetric performance. The need for anthropometric assessment, partographic monitoring, prompt identification of CPD and early possible caesarean section as well as prompt neonatal care are crucial in the prevention of adverse maternal and perinatal morbidity in short statured women.

\section{REFERENCES}

[1] Thomson AM. Maternal stature and reproductive efficiency. Eugen Rev 1959;51(3):157-62.

[2] Browne JC, McClure-Dixon G. In: Browne's antenatal care. $11^{\text {th }}$ edn. ELBS 1973:13.

[3] Desai P, Hazra M, Trivedi LB. Pregnancy outcome in short statured women. I Indian Med Assoc 1989;87(2):32-4.

[4] Maternal anthropometry and pregnancy outcomes. A WHO Collaborative study: introduction. Bull World Health Organ 1995;73 Suppl:1-6.

[5] Braveman PA, Tarirno E. Screening in primary health care setting priorities with limited resources. WHO, Genava 1994;56-7.

[6] Van Roosmalen J, Brand R. Maternal height and the outcome of labor in rural Tanzania. Int J Gynaecol Obstet 1992;37(3):169-77.

[7] Singh M. Text book of neonatology. $3^{\text {rd }}$ edn. CBS 1988:86-9.

[8] Intersalt: an international study of electrolyte excretion and blood pressure. Results for 24 hour urinary sodium and potassium excretion. Intersalt Cooperative Research Group. BMJ 1988;297(6644):319-28.

[9] Kappel B, Eriksen G, Hansen KB, et al. Short stature in scandinavian women. An obstetrical risk factor. Acta Obstet Gynaecol Scand 1987;66(2):153-8.

[10] Hin LY, Khairuddin Y, Ng KB. The predictive value of extremes of birth weight, mother's height and ethnic origin on the likelihood of emergency caesarean section. Asia Oceania J Obstet Gynaecol 1994;20(4):389-94.

[11] Parsons MT, Winegar A, Siefert L, et al. Pregnancy outcome in short women. J Reprod Med 1989;34(5):357-61.

[12] Pradhan N, Dali S. Pregnancy outcome in relation to the height of Nepalese women. J Inst Med 1992;14:179-91.

[13] Theodore K, Able R, Sampath Kumar V. Epidemiological correlates of low birth weight rural Tamil Nadu. Indian J Pediatr 1992;59:299-304.

[14] Camilleri AP. The obstetric significance of short stature. Eur J Obstet Gynaecol Reprod Biol 1981;12(6):347-56.

[15] Mahomed K, Bernadette M, Sarah M, et al. Maternal height-how high is the risk of short stature? J Obstet Gynaecol 1995;15(2):76-80. 